\title{
High variation in roost use by Dunlin wintering in California: Implications for habitat limitation
}

\author{
JESSE R. CONKLIN, MARK. A. COLWELL and NANCY W. FOX-FERNANDEZ
}

\begin{abstract}
Summary
Effective shorebird conservation requires a greater understanding of use and availability of hightide roosts in coastal non-breeding areas. In this paper, we explore 1 ) variation in use of roosts; 2) landscape and environmental correlates of roost use; and 3) responses to predators and humans at roosts, to evaluate roost availability for a wintering population of Dunlin Calidris alpina pacifica at Humboldt Bay, CA, USA. For four winters (2002-2005), Dunlin use of particular roosts was highly variable at the population and individual level, even at the most-used roosts. In any given day, week, or month, most Dunlin roosts were unused, and we continued to record new roosts even in the fourth year of study. Although roost use was influenced by landscape attributes, time of day, and environmental conditions, these variables left most variation in roost use unexplained. Dunlin departures from roosts were associated with the presence of avian predators, but not with human activity. Collectively, these observations revealed no strong evidence that roost availability was limited. This contrasts with findings of other studies, even after considering differences in methodology and spatial scale of analysis. We discuss implications for the interpretation of movement data, protection and/or creation of roosting habitat, and assessment of roost quality.
\end{abstract}

\section{Introduction}

Habitat loss and degradation are principal causes of population declines in birds. Recent evidence indicates that many populations of shorebirds (suborder Charadrii) are declining (Brown et al. 2001, Morrison et al. 2001, Thomas et al. 2006), and that these declines are largely attributable to loss and degradation of wetland habitats, particularly in non-breeding areas (Senner and Howe 1984, Myers et al. 1987, Brown et al. 2001). For wintering shorebirds, foraging areas and roosts, where individuals rest and perform maintenance behaviour while not feeding, form a 'functional unit' (Tamisier 1985, Luís and Goss-Custard 2005), providing for the essential needs of a local population. In coastal environs, the movements of wintering shorebirds are often predictable, with flooding tides regularly forcing individuals to roosts in close proximity to foraging areas.

The conservation of shorebird populations based on threats to wintering habitat therefore requires a focus on both foraging habitat and roosts (Rogers 2003). A common view is that roosting habitat is in short supply and requires protection and/or creation. This conclusion derives from several pieces of evidence, based on studies of populations and individuals. First, large flocks often use a few roosts on a predictable schedule (Hale 1980). Human disturbance at these roosts is argued to be of conservation concern because birds are frequently disturbed at roosts (e.g. Rogers et al. 2006b), and changes in roost location have been correlated with increases in human activity (e.g., Pfister et al. 1992). A second line of evidence that roosting habitat is limited derives from movements of individuals. Several studies have shown that wintering shorebirds use a small number of roosts, often in close proximity to their most valuable foraging areas (e.g., Dias et al. 2006, Rogers et al. 2006a). 
Traditional use of roosts (i.e., large numbers of birds occurring predictably at a roost day after day) may indicate the extent to which habitat is in short supply. A population limited to a few roosts may be especially vulnerable to human disturbance (Gill et al. 2001b) or constrained in feeding options (Dias et al. 2006, Rogers et al. 2006a). If this is the case, management actions can improve conditions and increase populations. For example, the concentration of a population at a few roosts has been used to argue for the creation of new roosts (Burton et al. 1996, Rehfisch et al. 1996, 2003). These observations, however, assume that roosts are in short supply such that providing additional habitat would have positive consequences for individuals and populations. Clearly, then, understanding the dynamics of individual movements to and from roosts has conservation value.

In this paper, we use fine-scale roost use data at the individual and population level to evaluate the availability of roosting habitat for a wintering population of Dunlin Calidris alpina pacifica. To gauge whether or not roosting habitat was limited, we examined the number of roosts used by Dunlin and the frequency with which specific roosts were used at multiple time scales, and evaluated the contribution of landscape and environmental variables to variation in roost use. We also quantified the extent to which individuals departed roosts during a given high tide, to evaluate the ability of Dunlin to move to alternative roosts when faced with disturbance by predators and humans. We conclude by discussing the conservation implications of our findings.

\section{Methods}

\section{Study area}

Humboldt Bay, in coastal northern California, USA, is a Western Hemisphere Shorebird Reserve Network site of international importance (Harrington and Perry 1995). The bay is 22.5 $\mathrm{km}$ long and $7.2 \mathrm{~km}$ wide at its widest point, with a $62.4 \mathrm{~km}^{2}$ area of water overlaying tidal flats at mean high tide. Two uneven high and low tides (range: -0.70 to $2.70 \mathrm{~m}$ in winter) occur every $24 \mathrm{~h}$, with nocturnal high tides lower than diurnal high tides in winter. The bay consists of three basins, the largest and northernmost of which is Arcata Bay (Figure 1). High fidelity of radio-marked Dunlin to Arcata Bay (Conklin and Colwell 2007) suggests that foraging and roosting areas, including natural and human-altered habitats, represent a 'functional unit' (Tamisier 1985).

\section{Bay-wide surveys}

During winter, spring, and fall of 2002, we conducted 28 bay-wide surveys of shorebird roosts around Humboldt Bay, identifying 240 different roosts used by 30 shorebird species (Colwell et al. 2003). We recorded all roosting flocks (two or more individuals) during a 2 -h period bracketing predicted diurnal high tides, and mapped the flock locations on aerial photographs as polygons in ArcView GIS (ESRI, Redlands, CA). In the current paper, we restricted analysis of survey data to Dunlin observations that were spatially and temporally comparable with subsequent telemetry data (see below). We included 11 surveys spanning 2 January-24 March 2002 (hereafter 'Year $I^{\prime}$ ) covering nine survey routes within Arcata Bay. Focused on the bay perimeter, survey routes did not reflect the full spatial extent covered by telemetry. For most roosts, the methods of defining roost locations from survey and telemetry data were in agreement. However, telemetry lacked the spatial precision of direct flock observations in certain locations; in these cases, we combined multiple roosts derived from surveys for comparison with telemetry data.

For Year 1 , we defined incidence as the proportion of II surveys in which at least one Dunlin occurred at a roost; incidence ranged from 0.09 to 1.o. We determined the physical size of each roost in ArcView by calculating the cumulative area $\left(\mathrm{m}^{2}\right)$ occupied by the polygons representing flock observations at the roost. 


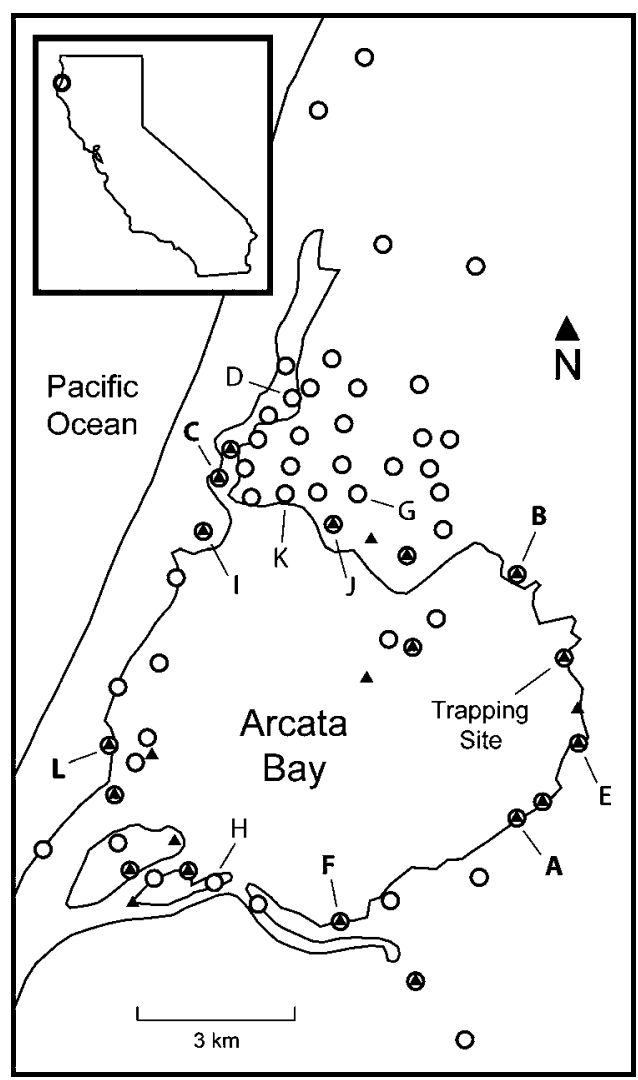

Figure 1. Arcata Bay, California study area and locations of 65 diurnal high-tide roosts used by Dunlin during Years $1-4$. Triangles indicate 23 roosts used during bay-wide surveys in Year 1. Circles indicate 59 diurnal roosts used by radio-marked birds during Years 2-4. Letters indicate 12 most-used roosts (Table 1 ). Letters in bold face indicate focal roosts in Year 2.

\section{Radio-telemetry}

During three winters of 2002-2005, we studied roost use of radio-marked Dunlin around Arcata Bay (Conklin and Colwell 2007). We trapped foraging Dunlin at a high-elevation tidal flat, fitted them with 1.1-1.5 g radio-transmitters (Holohil Systems Ltd., Carp, ON; 4-5 week battery life), and tracked them during a 2 -h period bracketing predicted high tides. We tracked 11 (2I December 2002-17 February 2003; hereafter 'Year 2'), 22 (24 November 2003-11 March 2004; 'Year 3'), and 25 individuals (2 December 2004-15 March 2005; 'Year 4') in successive years. We defined 'day' as the period from dawn (30 min before sunrise) to dusk (30 min after sunset), and 'night' as the remainder of the 24-h cycle. We tracked Dunlin for 51, 102, and 97 diurnal high tides in successive years, and 25, 66, and 84 nocturnal high tides. In analyses of incidence and abundance, we restricted telemetry data to diurnal high tides, for comparison with survey data in Year 1 and focalroost data in Years 2-3. For Years 2-4, we defined incidence as the proportion of diurnal high tides in which at least one radio-marked Dunlin occurred at a roost.

We categorized each roost into one of four habitats: low tidal $=$ tidal flat exposed on tides $<1.6 \mathrm{~m}(7$ roosts $) ;$ high tidal $=$ saltmarsh exposed except on tides $>2.4 \mathrm{~m}(20$ roosts $) ;$ terrestrial $=$ grazed pasture and ungrazed grassland ( 49 roosts); and manmade $=$ human-created substrates 
including islands, pilings, oyster rafts, riprap, water pipes, trestles, and pavement (1o roosts). If a roost contained multiple habitats, we classified it by the substrate used most often by Dunlin at that site.

We defined two landscape attributes of each roost: distance to foraging area (representing travel costs from tidal flats), and distance to cover (representing relative safety from predators). For each roost, we assigned a geometric center from which to measure distances in GIS. To represent foraging areas used by Dunlin prior to departing for roosts, we identified the seven highest-elevation tidal flats using an elevation map of Humboldt Bay (LIDAR survey, 2002). Foraging observations of Dunlin flocks (J. R. C., pers. obs.) and focal observations of radiomarked Dunlin (T. Adams, unpubl. data) both confirmed the high use of these foraging areas during flooding tides. We measured the distance from each roost to the edge of the closest foraging area. For distance to cover, we used the aerial photo to measure distance from the roost to the nearest structure, vegetation, or terrain feature $>1 \mathrm{~m}$ in height (excluding telephone poles and fence posts) which could obstruct view of an approaching predator. Using multiple regression, we examined how well landscape attributes of a roost predicted its relative use by Dunlin. The sample unit was the roost, and the dependent variable was number of telemetry detections in Years 2-4 combined. Because low tidal roosts were available only on neap tides ( $15 \%$ of high tides), we removed them from this analysis. Distance to foraging areas was squareroot transformed to achieve normality, and distance to cover was log-transformed.

Using canonical correlation, we examined the relationship between environmental conditions that varied daily (day of season, time of day, tide height, precipitation, and wind) and use of different roost habitats. Because roost habitat differed between day and night (Conklin and Colwell 2007), we analyzed diurnal and nocturnal high tides separately. The sample unit was the high tide ( $n=213$ diurnal or 154 nocturnal high tides with at least two marked Dunlin detected), and the habitat values were the proportion of detections in five categories (low tidal, high tidal, terrestrial, manmade, and 'flying'). Because we detected only one flying bird at night, we removed 'flying' from the nocturnal analysis. We coded day of season as: Day 1 (24 November) through 112 ( 15 March). For time of day, we calculated the minutes from the predicted high tide to dawn and to dusk, and used the lesser of the two values. Thus, small values indicate high tide coinciding with dawn or dusk, and values increase toward mid-day or mid-night, reflecting dawn and dusk as transition periods between diurnal and nocturnal space use (Conklin and Colwell 2007). Tide heights are daily verified peak water levels (m) at Humboldt Bay, North Spit from National Oceanic and Atmospheric Administration data (http://tidesonline.nos.noaa.gov). We included precipitation $(\mathrm{cm})$ at two temporal scales: totals that day (representing current rainfall) and during the previous seven days (representing saturation of habitats by prior rainfall). Wind speeds are daily averages $\left(\mathrm{km} \mathrm{h}^{-1}\right)$. We retrieved weather data for Arcata, CA (within the study area) from the National Weather Service (http://www.weather.gov/climate).

To retain important features of our data, we treated telemetry detections as independent observations, each representing a choice made under current conditions. Despite repeated sampling of individual birds, we believe pseudoreplication did not influence our conclusions, as relative use of habitats and specific roosts was essentially unchanged whether the sampling unit was the detection, the bird, or the roost (J. R. C., unpubl. data). Successive observations of individuals were uncorrelated, due to low fidelity to roosts (Conklin and Colwell 2007) and an intervening low tide cycle between observations. Accordingly, Rogers et al. (2006a) found that roost choices made by individual knots (Calidris canutus and C. tenuirostris) on different tides were effectively independent.

\section{Focal-roost observations}

In Year 3, we conducted daily counts of Dunlin roosting at Klopp Lake $(n=97$ high tides from 24 November 2003-11 March 2004) during a 2-h period bracketing predicted high tides. When Dunlin abundance changed within a high tide, we used the count nearest the predicted high tide. We used multiple regression to evaluate the ability of environmental variables (see canonical 
correlation above) to predict Dunlin abundance at Klopp Lake. Dunlin counts, precipitation totals, and wind speed were log-transformed to achieve normality.

In Year 2, we conducted focal surveys of Dunlin roost use in relation to predators and human activity (Fox-Fernandez 2006). From I December 2002-6 April 2003, we conducted 9-11 surveys each at 10 of the most-used roosts in Year I survey data (Colwell et al. 2003). For the current paper, we restricted analysis to six focal roosts within Arcata Bay. For logistical reasons, we treated one roost (Mad River Slough) as two roosts (Mad R. Slough Pipe and Mad R. Slough Rafts, approximately $185 \mathrm{~m}$ apart) for focal surveys.

For each survey, two people continuously observed a roost for $1 \mathrm{~h}$ during the 2 -h high tide period. Observers recorded Dunlin abundance at the start and end of the 1 -h period. Using instantaneous scan-sampling, we recorded Dunlin behaviour at I-min intervals (6o scans per survey). We summarized behaviour as the proportion of the roosting flock in each of three categories: loafing $=$ bird stationary and at rest; alert = bird stationary with head erect and actively scanning surroundings; and flying.

Concurrently, observers recorded the total number of raptors within $200 \mathrm{~m}$ of the roost. Although we observed other avian predators, we only recorded likely predators of Dunlin: Peregrine Falcon Falco peregrinus, Merlin F. columbarius, Northern Harrier Circus cyaneus, and Cooper's Hawk Accipiter cooperii. Observers recorded any avian attack, defined as a stoop or stealth approach in obvious pursuit of Dunlin. We observed no mammalian predators during the study.

Also, observers recorded total number of humans within $200 \mathrm{~m}$ of the roost. Because there was minimal difference in Dunlin response to raw abundance of humans compared to values weighted with expected relative disturbance impacts according to different activities (FoxFernandez 2006), we treated each human equally for analysis, regardless of behaviour. At two roosts with nearly constant vehicle traffic within the $200 \mathrm{~m}$ area, observers counted passing cars for one minute immediately before and after each survey, averaged those numbers, and multiplied by 60 for a 1 -h estimate.

We calculated Dunlin abundance as the mean of the minimum and maximum flock size during the survey. To describe change in Dunlin abundance during a survey, we calculated the following coefficient:

Change $=(\mathrm{A}-\mathrm{B}) /($ mean of $\mathrm{A}+\mathrm{B})$,

where $A=$ number of Dunlin at end of survey, and $B=$ number of Dunlin at start of survey. Thus, the coefficient was negative when birds departed and positive when birds arrived during the survey, ranging between -2 and 2, regardless of Dunlin abundance.

To characterize Dunlin behaviour for each survey, we multiplied the sum of the proportion of observations spent loafing by o, alert by 1 , and flying by 2 , across the 60 behavioural scans. By summing these products, the resulting behavioural index varied from $0-120(0=$ all Dunlin loafed, and $120=$ all Dunlin were in flight the entire survey), with higher values indicating higher nervousness.

Using Kruskal-Wallis one-way ANOVA, we examined differences among roosts in Dunlin, raptor, and human abundance, and Dunlin behavioural index. Likewise, we evaluated whether raptor or human abundance varied among surveys when Dunlin numbers increased, decreased, or remained constant. We used Spearman rank correlation to determine whether among-roost variation in Dunlin abundance was related to raptor or human abundance. Similarly, we compared behavioural index to abundance of Dunlin, raptors, and humans. We used a MannWhitney $U$-test to compare human abundance on surveys with and without a decrease in Dunlin abundance at Klopp Lake.

\section{Results}

\section{Variation in roost use}

During Year 1, Dunlin used 23 roosts (16,336 total observations) in 11 surveys of Arcata Bay. Most roosts were used infrequently (Figure 2a); Dunlin used II roosts (48\%) on fewer than 

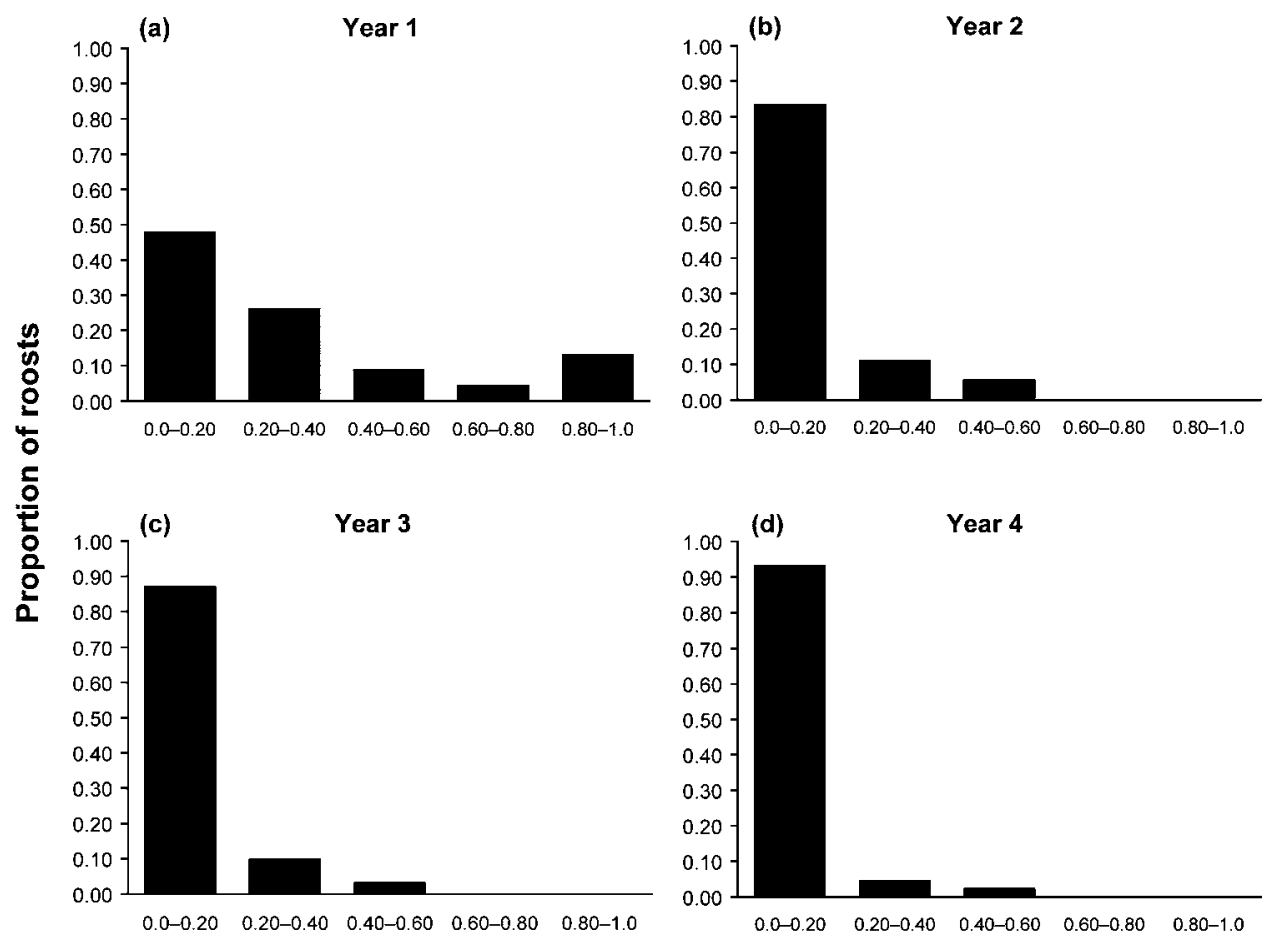

\section{Incidence}

Figure 2. Most diurnal roosts at Arcata Bay, CA were used infrequently by Dunlin, whether assessed by bay-wide surveys or movements of radio-marked individuals. Year 1 : incidence $=$ proportion of 11 bay-wide surveys in which Dunlin used that roost; $n=23$ roosts. Years 2-4: incidence $=$ proportion of days $(51,102$, and 97 days in successive years $)$ in which at least one radio-marked Dunlin used that roost; $n=18,31$, and 44 roosts, respectively.

$20 \%$ of surveys, and used only three roosts on more than $80 \%$ of surveys. On average, Dunlin used seven out of 23 roosts $\left(30 \%\right.$; range $=4^{-11}$ roosts) per survey. Roost use was highly concentrated: six roosts accounted for $89 \%$ of all observations. However, number of Dunlin at each of these six roosts was highly variable; variation (SD) was $77-170 \%$ of mean abundance.

During Years 2-4, radio-marked Dunlin used 86 roosts in Arcata Bay, of which 59 were diurnal roosts ( 957 detections of 55 individuals) and 61 were nocturnal roosts (650 detections of 49 individuals). As in Year 1 , Dunlin used most diurnal roosts infrequently (Figure $2 \mathrm{~b}-\mathrm{d}$ ); in each year, marked birds used $83-93 \%$ of roosts on fewer than $20 \%$ of high tides, and used only one roost on more than $40 \%$ of high tides. However, the roost with the highest incidence was in a different location in each year of telemetry (Table 1 ), and only two roosts were among the 10 highest-incidence roosts in all three years. Marked birds used only eight out of 59 roosts (14\%) in all three years.

We may not have recorded all Dunlin roosts in Arcata Bay. Radio-marked Dunlin continued to accumulate 'new' roosts late in Year 4, even after over 1,500 day and night detections (Figure 3). Additionally, radio-marked Dunlin never used three out of 23 diurnal roosts used in Year 1 , and used another three only at night.

Considering all four winters, incidence in Year 1 was a poor predictor of a roost's use in any subsequent year of telemetry (Table 1 ). Among the top six roosts in Year 1, only one (Klopp Lake) was among the top roosts in all three subsequent years; marked Dunlin used the other top 
Table 1 . Use of the 12 most-used diurnal roosts (incidence of $>0.10$ in at least one year) of wintering Dunlin at Arcata Bay, CA, varied greatly from year to year.

\begin{tabular}{|c|c|c|c|c|c|c|}
\hline \multirow[t]{2}{*}{ Roost Name } & \multirow[t]{2}{*}{ Roost ID ${ }^{\mathrm{a}}$} & \multirow[t]{2}{*}{ Habitat Type } & \multicolumn{4}{|c|}{ Incidence } \\
\hline & & & Year $1^{b}$ & Year $2^{c}$ & Year $3^{\mathrm{c}}$ & Year $4^{\circ}$ \\
\hline Indianola Cutoff ${ }^{\mathrm{d}}$ & A & manmade & 0.55 & 0.25 & 0.16 & o \\
\hline Klopp Lake ${ }^{\mathrm{d}}$ & B & manmade & 1.00 & 0.49 & 0.38 & 0.40 \\
\hline Mad River Slough $^{\mathrm{d}}$ & $\mathrm{C}$ & manmade & 0.73 & o & 0.14 & 0.16 \\
\hline Mad R. Slough E. Trestle & $\mathrm{D}$ & manmade & $\mathrm{na}^{\mathrm{e}}$ & o & 0.04 & 0.18 \\
\hline N. Bracut & E & manmade & 0.09 & o & 0.05 & 0.20 \\
\hline N. Eureka Slough ${ }^{\mathrm{d}}$ & $\mathrm{F}$ & high tidal & 0.82 & o & 0.05 & 0.04 \\
\hline N. Old Samoa Rd. & G & terrestrial & $n a^{e}$ & 0.14 & 0.34 & 0.02 \\
\hline NW. Eureka Slough & $\mathrm{H}$ & high tidal & o & o & 0.04 & 0.15 \\
\hline S. Mad River Slough & I & high tidal & 0.55 & $\mathrm{o}$ & 0.02 & 0.06 \\
\hline S. Old Samoa Rd. & $\mathrm{J}$ & terrestrial & 0.09 & 0.22 & 0.45 & 0.26 \\
\hline SW. Samoa Blvd. & $\mathrm{K}$ & terrestrial & o & 0.06 & 0.17 & 0.01 \\
\hline Vance Rd. Marsh ${ }^{\mathrm{d}}$ & $\mathrm{L}$ & high tidal & 0.82 & 0.02 & 0.25 & 0.46 \\
\hline
\end{tabular}

${ }^{a}$ Letters correspond to roost locations indicated on Figure 1.

${ }^{\mathrm{b}}$ In Year 1 , incidence $=$ proportion of 11 bay-wide surveys in which Dunlin used that roost.

${ }^{c}$ In Years 2-4, incidence = proportion of days (51, 102, and 97 days in successive years) in which at least one radio-marked Dunlin used that roost.

${ }^{\mathrm{d}}$ Roost was subject of focal surveys in Year 2.

${ }^{\mathrm{e}}$ Roost was not surveyed in Year 1 .

five roosts infrequently or not at all in at least one other year. Conversely, four roosts with little or no use in Year 1 had relatively high use in at least one other year.

High variation of roost use occurred within years as well (Figure 4). Among the six months with the best sample sizes for comparison (Years 3-4), proportional use by marked Dunlin varied considerably at nearly every roost. At four of the most-used roosts, proportional use varied from $<5 \%$ to $>28 \%$, depending on the month.

\section{Landscape and environmental correlates of roost use}

High-tide habitat use differed between day and night. Among 938 diurnal telemetry detections, $40 \%$ (29 roosts) were in terrestrial, $36 \%$ (10) in manmade, $20 \%(13)$ in high tidal and $4 \%(7)$ in low tidal habitat. Among 649 nocturnal detections, 81\% (43) were in terrestrial, 14\% (14) in high tidal, $3 \%$ ( 1 ) in low tidal and $2 \%(3)$ in manmade habitat.

Distance to both foraging area and cover differed between day and night roosts. Nocturnal use (proportion of telemetry detections among 79 roosts) was positively correlated with distance to cover $\left(\beta^{\prime}=0.88, P<0.01\right)$, which explained $26 \%$ of the variation, but not significantly correlated with distance to foraging area. Neither landscape attribute was significantly correlated with diurnal use, although there was a trend of diurnal use increasing with proximity to foraging areas ( $\beta^{\prime}=-0.01, P=0.09$ ). Physical size of a roost was also a poor predictor; among 23 diurnal roosts used in Year 1 , area (range $=1,310-120,025 \mathrm{~m}^{2}$ ) was not related to incidence among 11 surveys $\left(r^{2}=0.003, P=0.79\right)$ or average flock size $\left(r^{2}=0.001, P=0.99\right)$.

Environmental conditions were weakly correlated with roost habitat both day and night. During the day, significant correlations of the variable sets along four canonical axes collectively explained only $23 \%$ of the overall variation (Table 2 ). At night, variable sets were significantly correlated along two axes, explaining only $18 \%$ of the variation (not shown).

Environmental variables were also poor predictors of use of a specific roost. In Year 3, Dunlin were present at Klopp Lake during 74 of 97 diurnal high tides $(76 \%)$, and flock size varied greatly $($ mean $=930, \mathrm{SD}=927$, range $=10-4,000)$. Environmental variables explained little of 


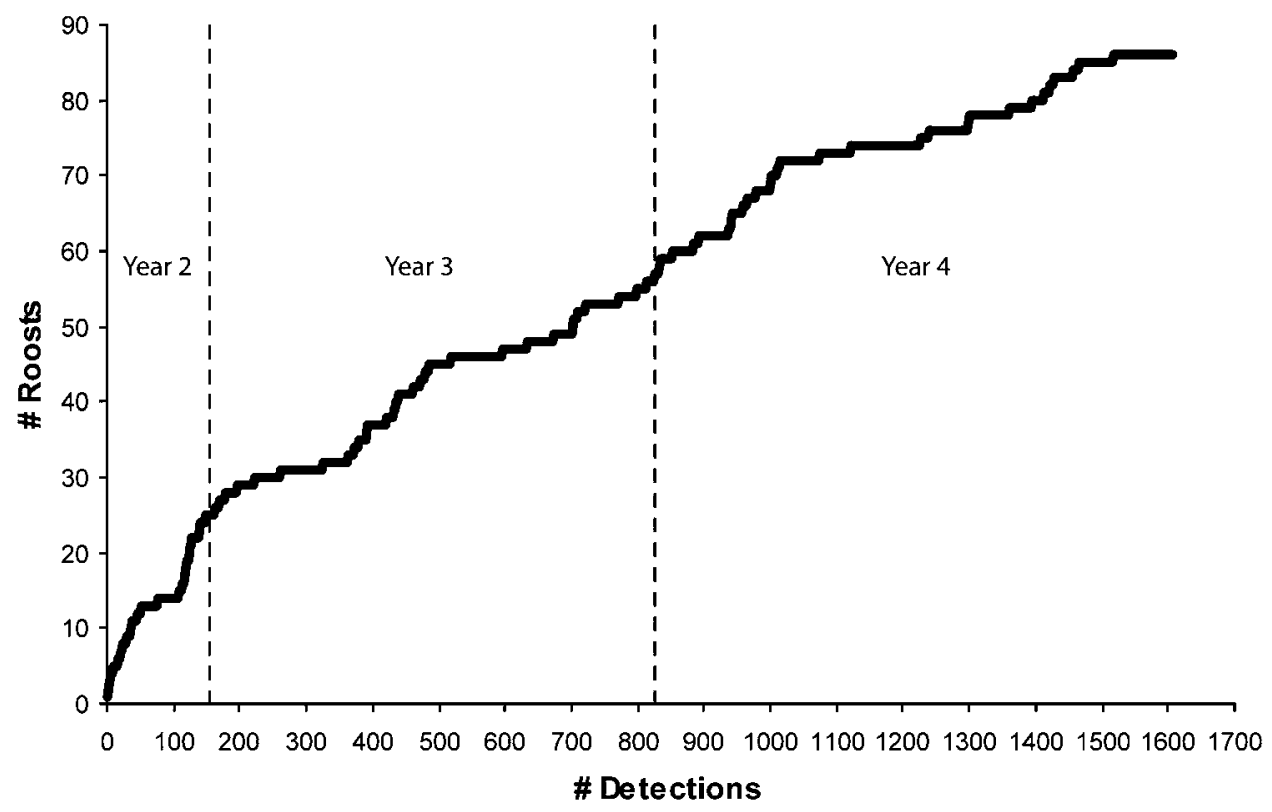

Figure 3. Total number of roosts used by radio-marked Dunlin at Arcata Bay, CA did not level off even after three winters (Years 2-4; 1,607 diurnal and nocturnal detections of 55 birds).

this variation; only wind speed correlated significantly with Dunlin abundance $\left(\beta^{\prime}=-1.74, P=\right.$ o.02), and the three best variables (wind, precipitation day of survey, and tide height) collectively accounted for only $20 \%$ of the variation.

We often detected a radio-marked bird at multiple locations during a single high tide (108 of 957 total diurnal detections). On 65\% (70 of 108) of these occasions, we recorded the individual at two or three roosts, often 5-7 km apart. Other times, we detected the bird at one roost and elsewhere in flight during the same high tide. These observations represent a conservative estimate of within-tide movements, because we did not always follow marked individuals throughout the 2-h period. Nineteen percent (21 of 108) of movements appeared related to tide, when a particular roost became inundated or exposed during the survey period. Twenty percent (22 of 108) of movements occurred within I h of dawn or dusk, and may represent movements between diurnal and nocturnal roosts.

Focal roost surveys in Year 2 also revealed frequent within-tide movements. During the $1-h$ high-tide survey, Dunlin numbers at the roost either increased or decreased on $44 \%$ (27 of 61) of surveys. Proximity to dawn or dusk or tide-related changes in roost availability during the survey were likely causes of Dunlin movements in only three of these cases.

\section{Effects of predators and human activity}

Dunlin abundance varied among six focal roosts $\left(H_{5}=14.37, P<0.03\right.$; Figure 5a), as did raptor abundance $\left(H_{5}=16.60, P<0.01\right.$; Figure $\left.5 \mathrm{~b}\right)$. Among-roost variation in Dunlin abundance was not significantly related to raptor abundance $\left(r_{\mathrm{s}}=0.36, n=6, P>0.50\right)$. Behavioural index of Dunlin did not vary significantly among roosts $\left(H_{5}=3.39, P>0.50\right.$; Figure $\left.5 \mathrm{a}\right)$.

When we included passing cars, three roosts adjacent to roads averaged 2,393 (Indianola Cutoff), 2,616 (N. Eureka Slough), and 415 (Vance Rd. Marsh) humans per survey, compared to 2-33 humans per survey at the remaining roosts. Because these dramatic differences did not appear to influence Dunlin abundance or behavioural index at roosts (Figure 5a), we removed 


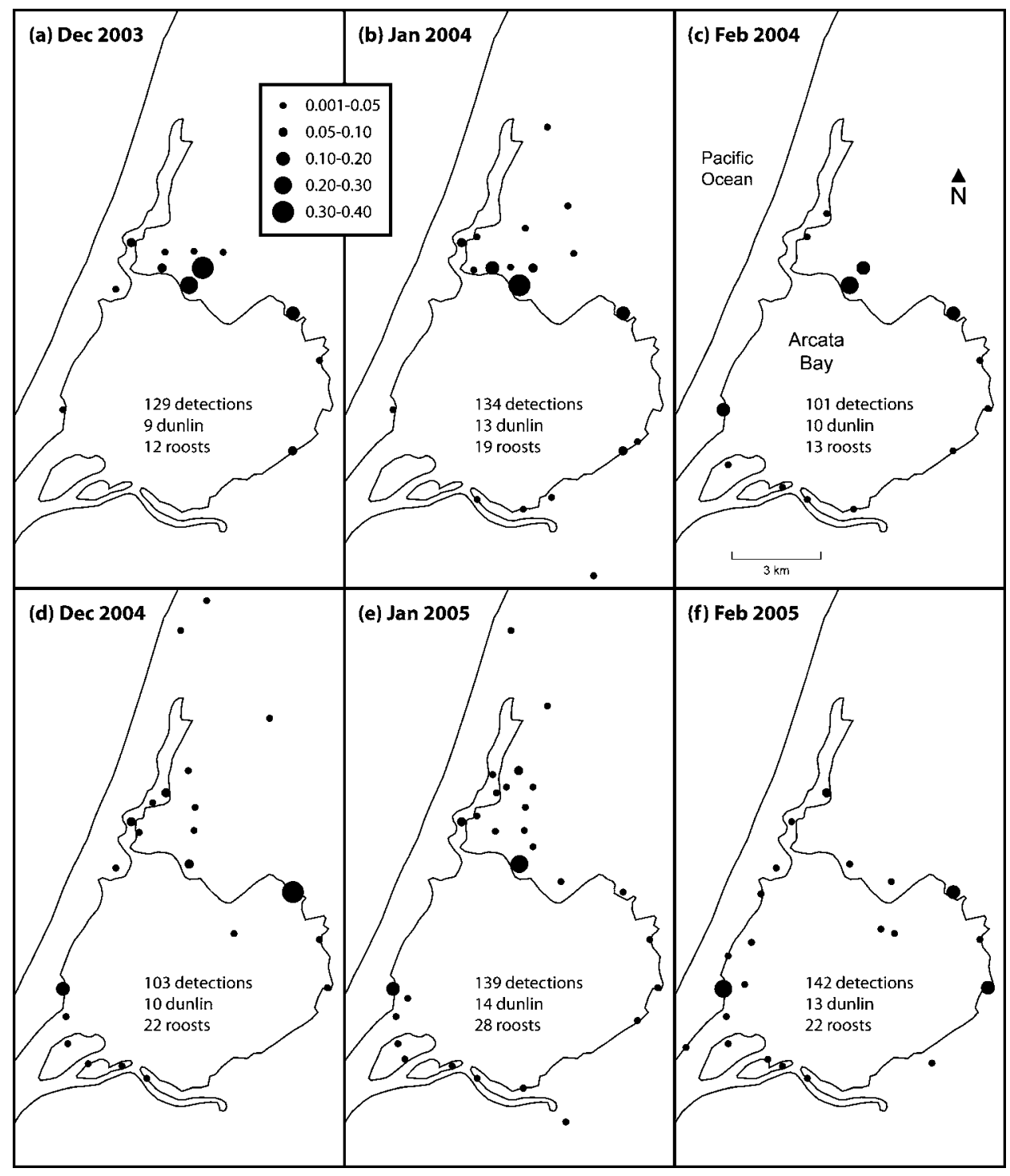

Figure 4. Monthly variation in proportional use (number of detections) of diurnal roosts by radio-marked Dunlin at Arcata Bay, CA during two winters (Years 3-4).

passing cars from further analyses. Without cars, human abundance still varied among roosts $\left(H_{5}=43.51, P<0.01\right.$; Figure $\left.5 \mathrm{~b}\right)$, but was not significantly related to among-roost variation in Dunlin abundance $\left(r_{\mathrm{s}}=0.71, n=6, P>0.10\right)$.

On average, Dunlin spent $67 \%$ of survey time loafing, $5 \%$ alert, and $28 \%$ flying. Across surveys at all roosts, behavioural index increased (i.e., birds became more nervous) with increasing Dunlin $\left(r_{\mathrm{s}}=0.39, n=41, P<0.02\right)$, raptor $\left(r_{\mathrm{s}}=0.42, n=41, P<0.01\right)$, and human abundance $\left(r_{\mathrm{s}}=0.37, n=41, P<0.02\right)$. Raptor abundance was related to whether Dunlin numbers increased, decreased, or remained constant during a survey $\left(H_{2}=8.08, P<0.03\right.$; Figure 6a); specifically, there were more raptors when Dunlin decreased than when numbers 
Table 2. In canonical correlation analysis, environmental conditions were significantly correlated with diurnal roost habitat, but explained only $23 \%$ of overall variation (Years $2-4 ; n=213$ diurnal high tides).

\begin{tabular}{|c|c|c|c|c|c|}
\hline \multirow[b]{2}{*}{ Environmental Variables } & \multicolumn{5}{|c|}{ Canonical Variables } \\
\hline & $X_{1}$ & $\mathrm{X}_{2}$ & $\mathrm{X}_{3}$ & $\mathrm{X}_{4}$ & $\mathrm{X}_{5}$ \\
\hline Day of season & -0.49 & -0.28 & -0.48 & -0.53 & 0.30 \\
\hline Proximity to dawn/dusk & 0.29 & -0.77 & -0.51 & 0.16 & -0.17 \\
\hline Tide height & 0.78 & -0.51 & 0.24 & -0.26 & -0.04 \\
\hline Precipitation day of survey & 0.62 & 0.40 & -0.25 & 0.16 & 0.61 \\
\hline Precipitation previous week & 0.40 & 0.52 & -0.10 & -0.06 & -0.58 \\
\hline Wind speed & 0.51 & 0.28 & -0.50 & -0.34 & 0.05 \\
\hline Roost Variables & $Y_{1}$ & $\mathrm{Y}_{2}$ & $\mathrm{Y}_{3}$ & $\mathrm{Y}_{4}$ & $\mathrm{Y}_{5}$ \\
\hline Low tidal & -0.59 & 0.63 & -0.12 & 0.42 & -0.23 \\
\hline High tidal & -0.55 & -0.44 & -0.64 & -0.26 & 0.20 \\
\hline Manmade & -0.25 & -0.60 & 0.73 & 0.18 & -0.13 \\
\hline Terrestrial & 0.86 & 0.44 & -0.27 & -0.04 & -0.03 \\
\hline Flying & -0.18 & 0.43 & $0.4^{2}$ & -0.57 & 0.53 \\
\hline Canonical Variate & 1 & 2 & 3 & 4 & 5 \\
\hline Canonical Correlation & 0.68 & 0.45 & 0.37 & 0.22 & 0.11 \\
\hline$r^{2}$ & 0.46 & 0.20 & 0.14 & 0.05 & 0.01 \\
\hline$F$ & 8.2 & $4 \cdot 7$ & 3.8 & 2.2 & 1.4 \\
\hline df & 30 & 20 & 12 & 6 & 2 \\
\hline$P$ & $<0.01$ & $<0.01$ & $<0.01$ & 0.05 & 0.26 \\
\hline Cumulative \% explained ${ }^{\mathrm{a}}$ & 13.7 & 19.0 & 22.3 & 22.9 & \\
\hline
\end{tabular}

${ }^{\mathrm{a} C}$ Cumulative \% variation in $\mathrm{Y}$ variables explained by $\mathrm{X}$ variables in significantly correlated axes.

remained constant. Human abundance was not related to changes in Dunlin numbers during a survey $\left(H_{2}=5.24, P>0.05\right.$; Figure $\left.6 \mathrm{~b}\right)$.

Abundance of Dunlin, raptors, and humans (without cars), as well as variation in all three measures, were greatest at one roost (Klopp Lake; Figure 5). Raptor attacks occurred during five of 11 surveys at Klopp Lake (1-8 attacks per survey), compared to just two of 50 surveys at all other roosts combined. Dunlin at Klopp Lake were most likely to depart during a survey; the average coefficient of change in Dunlin numbers was - 0.73 , compared to 0.00-0.10 for the other five roosts. Raptor attacks occurred on four out of five surveys when Dunlin departed the Klopp Lake roost. There was no difference in human abundance on surveys at Klopp Lake with and without a decrease in Dunlin abundance $\left(U=7.0, n_{1,2}=5, P>0.20\right)$.

\section{Discussion}

Several important findings emerge from our study. First, there was no apparent shortage of roosting habitat for the wintering population of Dunlin at Arcata Bay, California. Second, landscape and environmental variables explained only a small proportion of the daily variation in Dunlin roost use. Finally, individuals were more nervous in larger roosting flocks, and they were more likely to depart roosts during a given high tide when predators (but not humans) posed a danger to them. These findings have implications for management and conservation of shorebirds wintering in coastal regions, regardless of their population size.

\section{Abundance of roosting habitat}

Several findings indicate that there was no shortage of roosting habitat for Dunlin. We identified many (89) roosts, the vast majority of which were used infrequently, and the number of Dunlin 
(a)

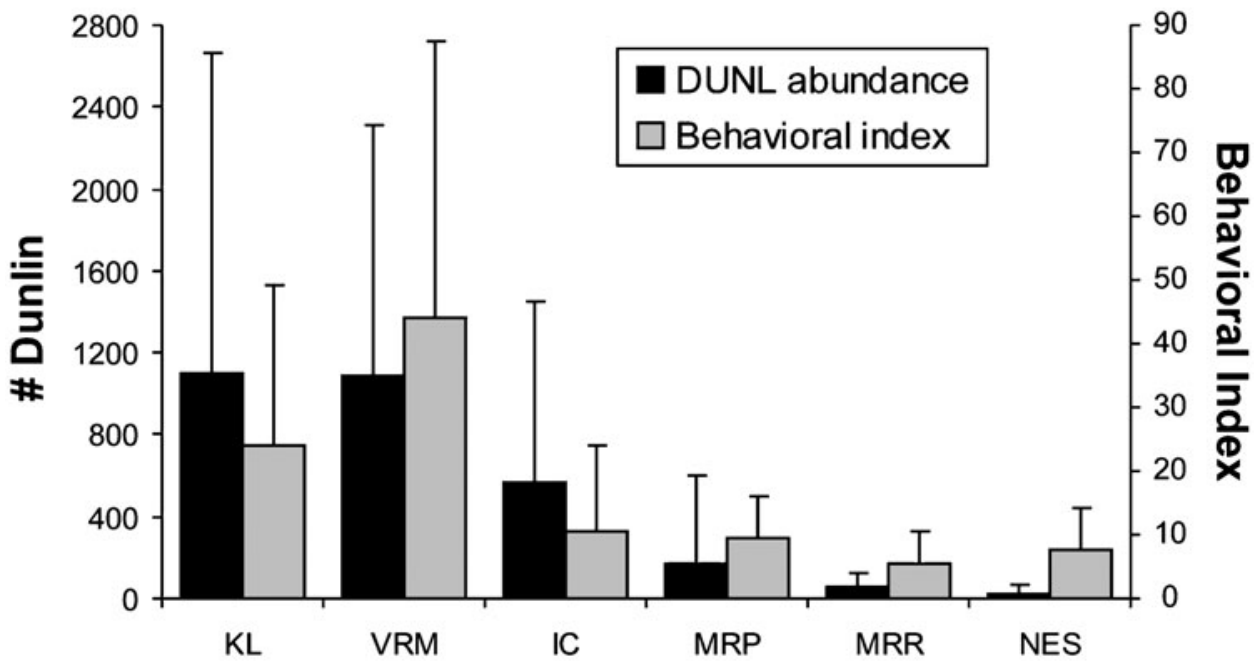

(b)

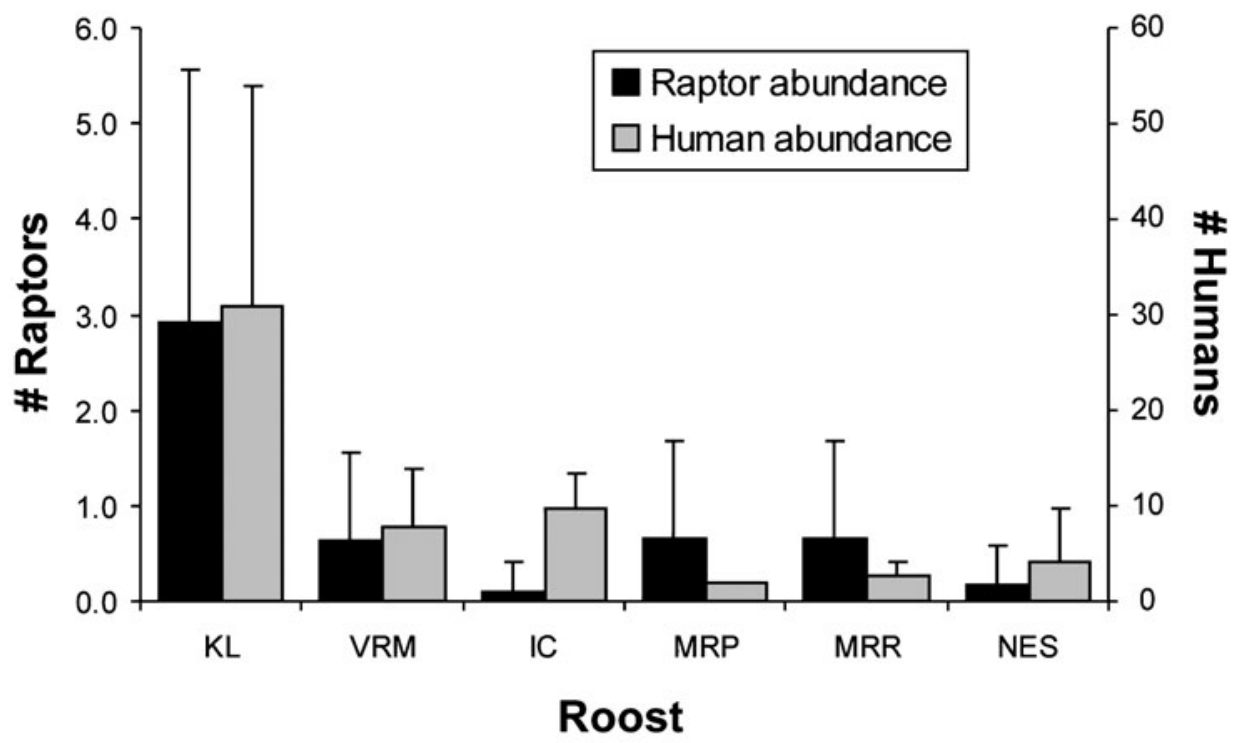

Figure 5. During focal surveys (Year 2), variation in Dunlin (a), raptor (b), and human abundance (b) was high, both among roosts and among surveys at a single roost. Behavioural index of Dunlin (a) did not vary significantly among roosts. KL $=$ Klopp Lake ( $n=11$ surveys); VRM $=$ Vance Rd. Marsh $(n=11) ;$ IC $=$ Indianola Cutoff $(n=10) ;$ MRP $=$ Mad R. Slough Pipe $(n=9) ; \operatorname{MRR}=\operatorname{Mad}$ R. Slough Rafts $(n=9) ; \mathrm{NES}=\mathrm{N}$. Eureka Slough $(n=11)$. Error bars indicate standard deviation. 


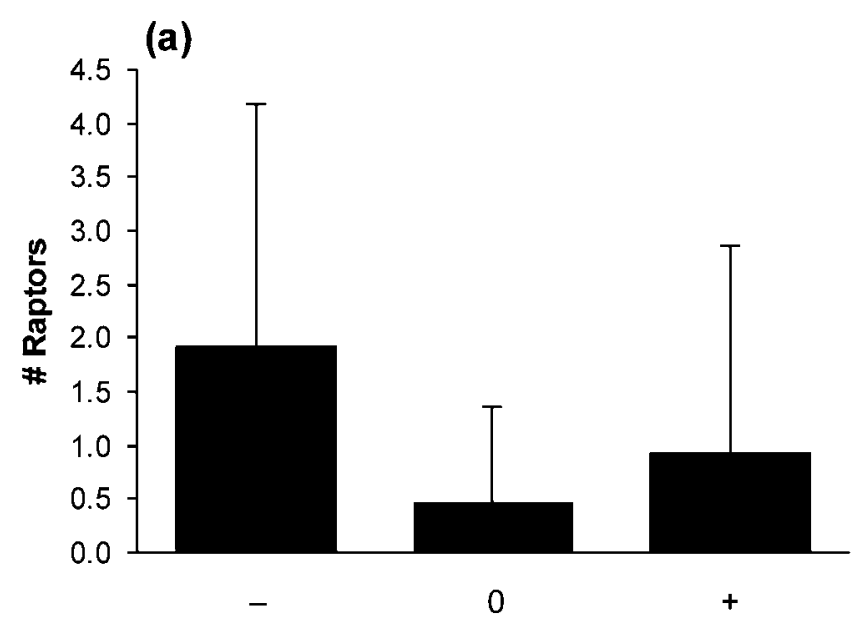

(b)

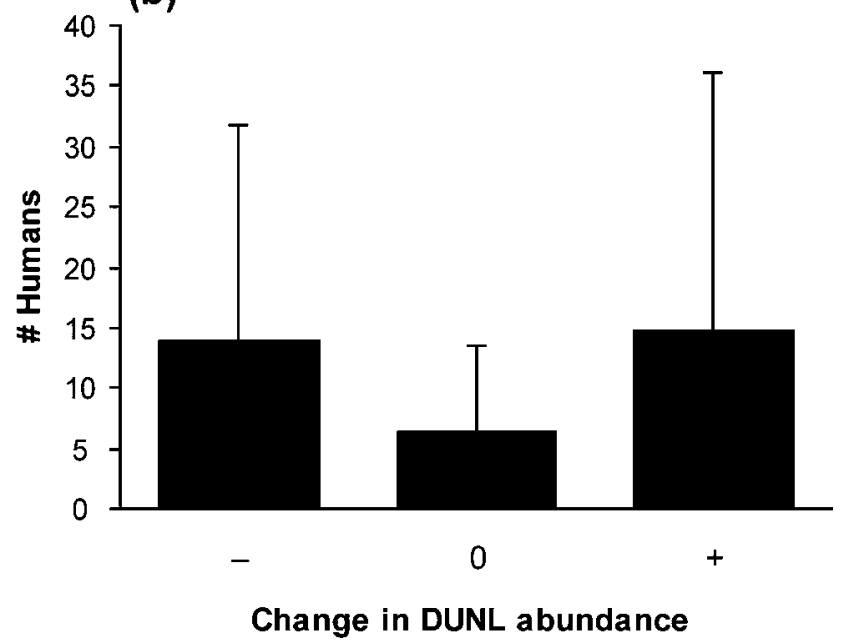

Figure 6. During focal surveys (Year 2), Dunlin were more likely to depart a roost when raptors were most abundant (a), but departures were not related to human abundance (b). $-=$ number of Dunlin decreased during survey $(n=13$ surveys); o $=$ no change $(n=34$ surveys $) ;+=$ increase $(n=14$ surveys). Error bars indicate standard deviation.

at even the most-used roosts was highly variable. This reflects individuals moving frequently among these roosts on a daily basis (Conklin and Colwell 2007). In any given day, week, or month, most roost habitat was unused. High flock counts indicate that at least 16 diurnal roosts in Arcata Bay can accommodate 2,000-6,000 roosting Dunlin each; the local population is approximately $10,000-12,000$ individuals (J. R. C., unpubl. data). In addition, we continued to identify 'new' roosts even after three winters of telemetry, suggesting that we have yet to identify all possible roosts. Most roosts were located around the periphery of the tidal flat and near other roosts, indicating Dunlin generally did not travel far from intertidal foraging areas, particularly during the day. Moreover, there was no relationship between the frequency of use by Dunlin and physical area of a roost. Collectively, these observations suggest that wintering Dunlin have many options when they choose a roost site. 
Our findings contrast with the conventional view that roosts are 'traditional' sites used predictably (i.e., on a daily basis; Hale 1980) by individuals (Colwell et al. 2003). These results also differ from studies around the world indicating that shorebirds have a limited number of roosts from which to choose. For example, roosts at Roebuck Bay, Australia were separated by as much as $25 \mathrm{~km}$, making movement among roosts an energetically costly endeavour (Rogers 2006b). At the Tagus estuary in Portugal, location and limited number of available roosts may cause Dunlin to underuse otherwise suitable foraging areas (Dias et al. 2006).

The very high number of roosts we described relative to comparably sized areas in other studies (Rehfisch et al. 1996, 2003, Dias et al. 2006, Leyrer et al. 2006, Rogers et al. 2006a) results from several factors. First, we used hand-held telemetry to identify every high-tide location used by marked birds, both day and night. Roost studies based on colour-marked birds or automated telemetry stations are to some extent limited to diurnal observations and/or previously identified roosts, and thus may not identify all available roosts. Second, we defined roosts at the finest possible spatial scale, resulting in multiple roosts that other researchers may have considered a single roost.

Beyond these methodological differences, however, we believe our data reflect actual differences in roost availability between Humboldt Bay and other estuaries. Although the perimeter of the bay is certainly altered from its natural state, the local human population remains relatively small $(<50,000)$, and shorebirds are not faced with the aggressive development or intensive human use of natural areas seen in more urban estuaries. As a result, Dunlin have numerous available roosts, which are not subjected to the high levels of disturbance reported in other studies (e.g., Pfister et al. 1992, Rogers et al. 2006b).

\section{Unpredictable use of roosts}

A second finding that reflects on the abundance and quality of roosting habitat was that variation in Dunlin use of roosts was poorly explained by landscape and environmental variables. Physical area, distance to cover, and distance to feeding areas are all relatively stable attributes that may contribute to differential use among roosts (Luís et al. 2001, Rogers 2003). Safety appeared to have a greater influence on nocturnal roost choice, as distance to cover was correlated with nocturnal but not diurnal use of roosts (Rogers et al. 2006a). Diurnal roosts were closer to the bay (Conklin and Colwell 2007), and the trend of increasing diurnal use with proximity to intertidal foraging areas, though perhaps statistically weakened by our static definition of foraging areas, was consistent with other studies (Furness 1973, Luís and Goss-Custard 2005, Dias et al. 2006, Rogers et al. 2006a). However, the ability of these variables to explain variation in use among roosts was low.

On a finer temporal scale, environmental factors that vary daily may affect roost use such that different roosts are favored under different conditions (Rogers et al. 2006b). However, substantial variation in Dunlin abundance at the most-used diurnal roost (Klopp Lake) was largely unexplained by the combined influence of day of season, time of day, tide height, precipitation, and wind. Even at a coarser spatial scale of analysis (habitat type), these variables were poor predictors of Dunlin roost use, although significant relationships in the canonical correlation reflected several expected trends (e.g., increased use of intertidal roosts during neap tides, increased use of pastures during precipitation, decreased use of exposed habitats during high winds, etc.).

The simple fact that some roosts were used more often and by greater numbers of Dunlin than others suggests that roosts varied in quality. The 'buffer effect' (Brown 1969, Gill et al. 2001a) predicts consistently high use of high-quality sites, while use of low-quality sites is densitydependent, increasing when high-quality sites 'fill up.' However, we detected no dramatic within-season changes in Dunlin abundance in the study area that would explain changes in roost use. In addition, variation was high even at the most-used diurnal roosts, which would often go unused for days or weeks at a time, and the top-ranked roosts varied by week, month, 
and year. This shows that less-used roosts were not simply of poor quality and used only when preferred roosts were unavailable. Rather, it suggests that suitability of a given roost was highly dynamic, even beyond the daily variation in environmental conditions.

Although we observed no obvious changes in habitat within the study site that would explain specific changes in Dunlin roost use, we did not specifically monitor attributes of roosts that may change over time, such as vegetation height or elevation in relation to tide. However, while such factors might contribute to monthly or yearly differences in use of particular roosts, they are unlikely to affect day-to-day patterns, much less changes in roost use within a particular high tide. The most likely cause of unexplained daily variation is disturbance by predators or humans.

\section{The Influence of predators and humans}

A last important finding, based on focal observations at roosts, was that departures of Dunlin during a given high tide correlated with activity of avian predators (principally falcons), but not humans. We believe the frequent movement of individuals among roosts was most strongly influenced by avian predators, which may help to explain the weak relationships we found between roost use and landscape and environmental variables.

Among focal roosts, Klopp Lake had the greatest Dunlin abundance, but also the greatest raptor abundance and frequency of raptor attacks. This probably reflects both the high relative quality of the Klopp Lake roost (it is close to the highest elevation tidal feeding area, and consists of manmade islands which provide high visibility and relative safety) and the inability of Dunlin to effectively prevent encounters with falcons through roost choice (Arcata Bay provides abundant high perches for raptors, and highly-mobile falcons appear able to follow shorebird flocks wherever they feed or roost). However, Dunlin were also more likely to depart Klopp Lake within a high tide than other roosts, suggesting they were not obligated to remain when predation risk was high. When faced with disturbance at a roost, birds should depart only if the cost is less than that of withstanding the disturbance (although the cost of predation may be absolute), and if lower disturbance can be expected elsewhere (Ydenberg and Dill 1986, Gill et al. 2001b). That Dunlin readily departed roosts in response to predators, and occasionally used multiple roosts within a high tide, illustrates that alternative roosting options exist.

We occasionally observed large Dunlin flocks circling in flight for extended periods near high tide. Sustained high-tide flying by Dunlin has been linked to the absence of safe roosting habitat (Brennan et al. 1985, Tubbs et al. 1992, Dekker 1998, Hötker 2000). However, the diurnal canonical correlation indicated that high-tide flying was more strongly associated with time of day than with tide height (i.e., higher tides did not cause high-tide flying by reducing available habitat). For this reason, we consider high-tide flying in Arcata Bay to be a result of increased Dunlin movement and predation danger associated with dawn and dusk (Conklin and Colwell 2007), rather than an illustration of limited high-tide habitat per se.

Humans were not associated with Dunlin use or departure from roosts, for which there are several possible explanations. Because we used a fixed sampling area of $200 \mathrm{~m}$ around the roost, most recorded human activity probably occurred beyond the flush distance of Dunlin, which are relatively approachable (Davidson and Rothwell 1993). Also, Dunlin may be habituated to human presence that is not directly threatening (Hockin et al. 1992). Moreover, we chose focal roosts based on high Dunlin use, which probably resulted in part from the relative safety of these roosts from disturbance. In fact, four out of six focal roosts were surrounded by over $50 \mathrm{~m}$ of open water or saltmarsh, making close approach by humans (and terrestrial predators) unlikely. In general, human disturbance at local roosts appears to be low; we rarely observed Dunlin flushing from roosts due to human activity during telemetry work, although flushing due to predators was quite common. We believe that the availability of habitat allows Dunlin to choose roosts at which human disturbance is unlikely.

Dunlin were more nervous in larger flocks, and the energetic costs of this represent a tradeoff to the anti-predator benefits of flocking (Cresswell 1994). The presence of conspecifics (as well as 
individuals of other species) must be considered, along with presence of predators and humans, as a facet of roost quality which may vary temporally. In addition, this potential cost of being in a large flock may call into question the use of shorebird abundance as an indication of relative roost quality.

\section{Conservation implications}

Important conservation implications derive from our findings. Recent papers (Burton et al. 1996, Rehfisch et al. 1996, 3, Dias et al. 2006) have used site fidelity (limited movements) of wintering shorebirds as the basis for arguments regarding the protection and/or creation of habitat. For example, Rehfisch et al. (1996, 2003) found that many marked individuals of several shorebird species wintering at two estuaries in the U.K. (the Wash and Moray Firth) were recaptured at the same roosts over multiple years. The authors argued that high site-fidelity (based on recaptures within an estuary 'section' spanning many kilometres) indicated roosting habitat was limited and therefore protection and/or creation of roosts was warranted. However, the scale of their analysis was inappropriate to the conclusion that individual birds were limited by roost availability. For example, Dunlin had high fidelity to Arcata Bay (equivalent to a section in their studies), but low fidelity to particular roosts within their home ranges (Conklin and Colwell 2007). We suggest that movement among roosts within the functional unit (i.e., the area used by individuals in their normal daily movements during the winter; Tamisier 1985) is the appropriate spatial scale of inference for management actions regarding roost availability, because human disturbance and development, as well as creation of roosts, will generally occur at this scale.

When extrapolating conservation recommendations from movement data, it is important to recognize that what birds are observed doing may not represent the limit of their capabilities. Hypothetically, were avian predators (and thus Dunlin inter-roost movements) greatly reduced in Arcata Bay, roost use might become more predictable, which could then be misconstrued as limitation. It is instructive that some authors have interpreted high site-fidelity as indicative of sufficient local resources making longer movements unnecessary (Warnock and Takekawa 1996, Leyrer et al. 2006), rather than of habitat limitation. Still, we believe careful use of movement data can be a useful index for habitat limitation, especially while clear demonstrations of the ultimate effects of habitat loss on individual survival and distribution (e.g., Burton et al. 2006) remain rare. Understanding how widespread and abundant species (such as Dunlin) behave in conditions of relatively unlimited habitat will help us to identify and address situations where species or populations are limited by habitat.

Compared to other estuaries worldwide, Humboldt Bay is relatively pristine, with moderate human impacts and abundant intertidal foraging areas in close proximity to roosting habitats for shorebirds. The loss of any one roost may be of minimal consequence to the wintering Dunlin population, and this is likely true for other species as well, given similarities among roost use patterns of the 14 most abundant shorebird species at Humboldt Bay (Colwell et al. 2003). However, given that roosts vary in use (and probably quality), there will be some minimum distribution of suitable roosting habitat around the bay necessary to sustain local shorebird populations. In addition, since suitability of roosts may be highly dynamic, it is important that roosts exist to allow response to variation in environmental conditions and predation danger, and to buffer against future circumstances (e.g., rise in sea level). The recognition that relative quality varies temporally is critical for efforts to describe roost quality (e.g., Luís et al. 2001, Rogers 2003). We suggest that the next step in conservation efforts is to quantify variation in factors affecting quality of roosting habitat.

\section{Acknowledgements}

We thank T. Adams, T. Danufsky, M. Lima, J. Meyer, and J. Roth for their essential contributions to the project. Scores of Humboldt State University students and others provided 
field and technical assistance, and we appreciate their efforts. We thank M. Rehfisch, D. Rogers, N. Warnock, Y. Zharikov, and one anonymous reviewer, whose comments on earlier drafts greatly improved the manuscript. This report was made possible by a U.S. Fish and Wildlife Service Coastal Programs grant. Field work was supported in part by the California Department of Fish and Game's Oil Spill Response Trust Fund through the Oiled Wildlife Care Network at the Wildlife Health Center, School of Veterinary Medicine, University of California, Davis. Additional support came from the HSU Office of Research and Graduate Studies, and the Friends of the Arcata Marsh. Research was approved by the HSU Institutional Animal Care and Use Committee.

\section{References}

Brennan, L. A., Buchanan, J. B., Herman, S. G. and Johnson, T. M. (1985) Interhabitat movements of wintering Dunlins in western Washington. Murrelet 66: 11-16.

Brown, J. L. (1969) The buffer effect and productivity in tit populations. Am. Nat. 103: 347-354.

Brown, S., Hickey, C., Harrington, B. and Gill, R. (2001) United States shorebird conservation plan. Second Edition. Manomet, MA: Manomet Center for Conservation Sciences.

Burton, N. H. K., Evans, P. R. and Robinson, M. A. (1996) Effects on shorebird numbers of disturbance, the loss of a roost site and its replacement by an artificial island at Hartlepool, Cleveland. Biol. Conserv. 77: 193-201.

Burton, N. H. K., Rehfisch, M. M., Clark, N. A. and Dodd, S. G. (2006) Impacts of sudden winter habitat loss on the body condition and survival of redshank Tringa totanus. J. Appl. Ecol. 43: 464-473.

Colwell, M. A., Danufsky, T., Fox-Fernandez, N. W., Roth, J. E. and Conklin, J. R. (2003) Variation in shorebird use of diurnal, hightide roosts: how consistently are roosts used? Waterbirds 26: 484-493.

Conklin, J. R. and Colwell, M. A. (2007) Diurnal and nocturnal roost site-fidelity of Dunlin (Calidris alpina pacifica) at Humboldt Bay, California. Auk 124: 677-689.

Cresswell, W. (1994) Flocking is an effective anti-predation strategy in redshanks, Tringa totanus. Anim. Behav. 47: 433-442.

Davidson, N. and Rothwell, P. (1993) Human disturbance to waterfowl on estuaries: conservation and coastal management implications of current knowledge. Wader Study Group Bull. 68: 97-105.

Dekker, D. (1998) Over-ocean flocking by Dunlins, Calidris alpina, and the effects of raptor predation at Boundary Bay, British Columbia. Can. Field Nat. 112: 694-697.

Dias, M. P., Granadeiro, J. P., Lecoq, M., Santos, C. D. and Palmeirim, J. M. (2006) Distance to high-tide roosts constrains the use of foraging areas by Dunlins: implications for the management of estuarine wetlands. Biol. Conserv. 131: 446-452.

Fox-Fernandez, N. W. (2006) Roost use by wintering Dunlin (Calidris alpina pacifica) at Humboldt Bay, CA.: relationship to predation danger and human activity. M.S. thesis, Humboldt State University, Arcata, CA.

Furness, R. W. (1973) Roost selection by waders. Scottish Birds 7: 281-287.

Gill, J. A., Norris, K., Potts, P. M., Gunnarsson, T. G., Atkinson, P. W. and Sutherland, W. J. (2001a) The buffer effect and large-scale population regulation in migratory birds. Nature 412: 436-438.

Gill, J. A., Norris, K. and Sutherland, W. J. (2001b) Why behavioural responses may not reflect the population consequences of human disturbance. Biol. Conserv. 97: 265-268.

Hale, W. G. (1980) Waders. London: Collins.

Harrington, B. and Perry, E. (1995) Important shorebird staging sites meeting WHSRN criteria in the U.S. Washington, D.C.: U.S. Dept. of the Interior, Fish and Wildlife Service.

Hockin, D., Ounsted, M., Gorman, M., Hill, D., Keller, V. and Barker, M. (1992) 
Examination of the effects of disturbance on birds with reference to the role of environmental impact assessments. J. Environ. Manage. 36: 253-286.

Hötker, H. (2000) When do Dunlins spend high tide in flight? Waterbirds 23: 482-485.

Leyrer, J., Spaans, B., Camara, M. and Piersma, T. (2006) Small home ranges and high site fidelity in red knots (Calidris c. canutus) wintering on the Banc d'Arguin, Mauritania. J. Orn. 147: $376-384$.

Luís, A. and Goss-Custard, J. (2005) Spatial organization of the Dunlin Calidris alpina L. during winter - the existence of functional units. Bird Study 52: 97-103.

Luís, A., Goss-Custard, J. D. and Moreira, M. H. (2001) A method for assessing the quality of roosts used by waders during high tide. Wader Study Group Bull. 96: 71-73.

Morrison, R. I. G., Aubry, Y., Butler, R. W., Beyersbergen, G. W., Donaldson, G. M., Gratto-Trevor, C. L., Hicklin, P. W., Johnston, V. H. and Ross, R. K. (2001) Declines in North American shorebird populations. Wader Study Group Bull. 94: 34-38.

Myers, J. P., Morrison, R. I. G., Antas, P. Z., Harrington, B. A., Lovejoy, T. E., Sallaberry, M., Senner, S. E. and Tarak, A. (1987) Conservation strategy for migratory species. Am. Sci. 75: 18-26.

Pfister, C., Harrington, B. A. and Lavine, M. (1992) The impact of human disturbance on shorebirds at a migration staging area. Biol. Conserv. 60: 1-12.

Rehfisch, M. M., Clark, N. A., Langston, R. H. W. and Greenwood, J. J. D. (1996) A guide to the provision of refuges for waders: an analysis of 30 years of ringing data from the Wash, England. J. Appl. Ecol. 33: 673-687.

Rehfisch, M. M., Insley, H. and Swann, B. (2003) Fidelity of overwintering shorebirds to roosts on the Moray Basin, Scotland: implications for predicting impacts of habitat loss. Ardea 91: 53-70.

Rogers, D. I. (2003) High-tide roost choice by coastal waders. Wader Study Group Bull. 100: 73-79.

Rogers, D. I., Battley, P. F., Piersma, T., van Gils, J. A. and Rogers, K. G. (2006a) Hightide habitat choice: insights from modelling roost selection by shorebirds around a tropical bay. Anim. Behav. 72: 563-575.

Rogers, D. I., Piersma, T. and Hassell, C. J. (2006b) Roost availability may constrain shorebird distribution: exploring the energetic costs of roosting and disturbance around a tropical bay. Biol. Conserv. 133: 225-235.

Senner, S. E. and Howe, M. A. (1984) Conservation of Nearctic shorebirds. Pp. $379-421$ in J. Burger and B. L. Olla, eds. Behaviour of marine animal, Vol. 5 . Shorebirds: breeding behaviour and populations. New York: Plenum Press.

Tamisier, A. (1985) Some considerations on the social requirements of ducks in winter. Wildfowl 36: 104-108.

Thomas, G. H., Lanctot, R. B. and Szekely, T. (2006) Can intrinsic factors explain population declines in North American breeding shorebirds? A comparative analysis. Anim. Conserv. 9: 252-258.

Tubbs, C. R., Tubbs, J. M. and Kirby, J. S. (1992) Dunlin Calidris alpina alpina in the Solent, southern England. Biol. Conserv. 6o: 15-24.

Warnock, S. E. and Takekawa, J. Y. (1996) Wintering site fidelity and movement patterns of western sandpipers Calidris mauri in the San Francisco Bay estuary. Ibis 138: 160-167.

Ydenberg, R. C. and Dill, L. M. (1986) The economics of fleeing from predators. Adv. Stud. Behav. 16: 229-249.

JESSE R. CONKLIN*, MARK. A. COLWELL, NANCY W. FOX-FERNANDEZ

Department of Wildife, Humboldt State University, Arcata, CA 95521, U.S.A.

* Author for correspondence; e-mail: conklin.jesse@gmail.com

Received 9 January 2007; revision accepted 22 October 2007 